\title{
Transcriptomic Analysis Reveals Candidate Genes Responding Maize Gray Leaf Spot Caused by Cercospora zeina
}

\author{
Wenzhu He ${ }^{1,2, *,+}$, Yonghui Zhu ${ }^{1,+} \mathbb{D}$, Yifeng Leng ${ }^{3,+}$, Lin Yang ${ }^{1}$, Biao Zhang ${ }^{1}$, Junpin Yang ${ }^{1}$, Xiao Zhang $^{2} \mathbb{D}$, \\ Hai Lan ${ }^{2}$, Haitao Tang ${ }^{1}$, Jie Chen ${ }^{1}$, Shibin Gao ${ }^{2}$, Jun Tan ${ }^{1}$, Jiwei Kang ${ }^{1}$, Luchang Deng ${ }^{1}$, Yan Li ${ }^{1}$, \\ Yuanyuan $\mathrm{He}^{1}$, Tingzhao Rong ${ }^{2}$ and Moju Cao ${ }^{2, *}$
}

1 Crop Research Institute, Sichuan Academy of Agricultural Sciences, Chengdu 610066, China; yhzhu86@hotmail.com (Y.Z.); ownmylife@163.com (L.Y.); 13908177069@163.com (B.Z.); y.junpin@263.net (J.Y.); 13808068781@163.com (H.T.); 18010503015@163.com (J.C.); tanjunbreeze@163.com (J.T.); kjwkd@163.com (J.K.); leo20060608@126.com (L.D.); zhangxiaoliyan@163.com (Y.L.); heyuan199301@163.com (Y.H.)

2 Maize Research Institute, Sichuan Agricultural University, Chengdu 611130, China; hunterzap@163.com (X.Z.); lanhai_maize@163.com (H.L.); shibingao@163.com (S.G.); rongtz@sicau.edu.cn (T.R.)

3 College of Agricultural Sciences, Xichang University, Xichang 615000, China; yifeng_71@163.com

* Correspondence: wenzu-he@163.com (W.H.); caomj@sicau.edu.cn (M.C.)

+ These authors contributed equally to this work.

check for updates

Citation: He, W.; Zhu, Y.; Leng, Y.; Yang, L.; Zhang, B.; Yang, J.; Zhang, X.; Lan, H.; Tang, H.; Chen, J.; et al. Transcriptomic Analysis Reveals Candidate Genes Responding Maize Gray Leaf Spot Caused by Cercospora zeina. Plants 2021, 10, 2257. https:// doi.org/10.3390/plants10112257

Academic Editors: Attila L. Ádám and Lorant Király

Received: 16 September 2021

Accepted: 12 October 2021

Published: 22 October 2021

Publisher's Note: MDPI stays neutral with regard to jurisdictional claims in published maps and institutional affiliations.

Copyright: (c) 2021 by the authors. Licensee MDPI, Basel, Switzerland. This article is an open access article distributed under the terms and conditions of the Creative Commons Attribution (CC BY) license (https:/ / creativecommons.org/licenses/by/ $4.0 /)$.

\begin{abstract}
Gray leaf spot (GLS), caused by the fungal pathogen Cercospora zeina (C. zeina), is one of the most destructive soil-borne diseases in maize (Zea mays L.), and severely reduces maize production in Southwest China. However, the mechanism of resistance to GLS is not clear and few resistant alleles have been identified. Two maize inbred lines, which were shown to be resistant (R6) and susceptible (S8) to GLS, were injected by C. zeina spore suspensions. Transcriptome analysis was carried out with leaf tissue at $0,6,24,144$, and $240 \mathrm{~h}$ after inoculation. Compared with $0 \mathrm{~h}$ of inoculation, a total of 667 and 419 stable common differentially expressed genes (DEGs) were found in the resistant and susceptible lines across the four timepoints, respectively. The DEGs were usually enriched in 'response to stimulus' and 'response to stress' in GO term analysis, and 'plant-pathogen interaction', 'MAPK signaling pathways', and 'plant hormone signal transduction' pathways, which were related to maize's response to GLS, were enriched in KEGG analysis. Weighted-Genes Coexpression Network Analysis (WGCNA) identified two modules, while twenty hub genes identified from these indicated that plant hormone signaling, calcium signaling pathways, and transcription factors played a central role in GLS sensing and response. Combing DEGs and QTL mapping, five genes were identified as the consensus genes for the resistance of GLS. Two genes, were both putative Leucine-rich repeat protein kinase family proteins, specifically expressed in R6. In summary, our results can provide resources for gene mining and exploring the mechanism of resistance to GLS in maize.
\end{abstract}

Keywords: maize; RNA-Seq; gray leaf spot; WGCNA; disease resistance

\section{Introduction}

Gray leaf spot (GLS) in maize, Cercospora zeina (C. zeina), is one of the most destructive foliar diseases. High humidity and mild temperature are favorable conditions for GLS infection [1]. Cercospora spores predominantly overwinter in diseased plant debris that remains on the soil surface [2], and conidia produced by the fungus are disseminated onto corn plants by wind and rain splash [3]. The mature GLS lesions run parallel to leaf veins with rectangular spots ranging in color from gray to tan. They first appear as small tan spots at the bottom leaf, and as the disease develops, the entire leaves and stem become withered. The disease causes substantial losses in yield (from $20 \%$ to $60 \%$, and even as high as $100 \%$ ) in severe cases [4-6]. 
The main methods of controlling GLS include avoiding the conservation of tillage, the application of chemical fungicides, and planting resistant hybrids $[7,8]$. As conserving tillage is important for preserving the economics of maize production, and chemical fungicides are not environmentally friendly, the selection of resistant hybrids is the most efficient and cost-effective method of controlling GLS [8,9].

GLS resistance is a complex phenotype that is influenced by environmental conditions and controlled by many minor quantitative trait loci (QTL) with additive effects [10-13]. In the last 20 years, many QTLs related to GLS resistance have been detected on all 10 maize chromosomes using various mapping populations $[6,10,11,13-20]$. Some of them can explain a total phenotypic variation of larger than $20 \%[15,20]$. Combining genome-wide association and linkage mapping, Kibe et al. [18] identified 14 QTLs across three DH populations, and 10 significant associated SNPs. Nine of the co-located candidate genes play roles in plant defense against pathogens. However, only a few of the primarily mapped QTL-derived genes have been finely mapped at present. $q$ Rgls2, which can increase the resistance percentage by more than $20 \%$, were mapped in $1-\mathrm{Mb}$ intervals, and 15 genes were predicted [21]. Qgls8 was detected by a near-isogenic line population derived from teosinte introgression, and delimited in a $130 \mathrm{~kb}$ region on chromosome 8 , including five predicted genes [22]. qGLS1.02, which can explain $6.86-36.24 \%$ of the phenotypic variation in GLS resistance, was narrowed to $\sim 314 \mathrm{~kb}$, including 12 candidate genes [23]. Qgls_YZ2-1, which was identified from two $\mathrm{DH}$ populations, was finely mapped into a 2.4-Mb region on chromosome 2 [19]. qRgls1.06, which was a major QTL that explained $~ 55 \%$ of phenotype variance, was localized in a $2.38-\mathrm{Mb}$ region on chromosome 1 [24]. In summary, despite the abundant GLS QTLs that were identified by the various mapping populations, only few GLS-resistant QTLs were finely mapped, and no GLS-resistant gene has been cloned to date. Thus, the mechanism of resistance to GLS has yet to be fully understood. Combining linkage mapping and omics data is a good strategy to identify the candidate genes related to GLS resistance.

Plants have evolved two types of defense mechanisms against pathogen invasion, i.e., PAMP-triggered immunity (PTI) and effector-triggered immunity (ETI) [25]. Many of the key enzymes are involved in two mechanisms that play roles in plant defense. The phenylalanine ammonia-lysases (PALs) are key enzymes for the biosynthesis of salicylic acid (SA) and the phenylpropanoid pathway of higher plants. The SA is a plant hormone that is required to initiate systemic acquired resistance [26]. The products of the phenylpropanoid pathway are key contributors to disease resistance [27]. PALs contribute to broad-spectrum resistance (BSR) mediated by nucleotide-binding domain, leucine-rich repeat-containing (NLR) proteins and RNA-binding proteins [28,29]. Catalase (CAT) can degrade hydrogen peroxide, which works as a kind of signaling molecule for plant defense in plants [30,31], into water and molecular oxygen. Polyphenol oxidase (POD) is involved in the response to both biotic and abiotic stresses in plants, including plant defense, plastidic oxygen, and the phenylpropanoid pathway [32]. Proline is a widely distributed compatible solutes in plants, and acts as antioxidative defense molecule and signaling molecule during stress [33]. Therefore, the dynamic changes in physiological characteristics caused by these enzymes and components can reflect the intensity of response to the $C$. zeina infection, acting as indicator when dividing the GLS-resistance or susceptible inbred lines.

In recent years, as transcriptome analysis can provide an efficient way of assessing variation in the global expression of genes, RNA-Seq analysis has been used to study plant-pathogen interactions [34-37]. RNA-Seq analysis, from a previous study of GLS, showed that different forms of kauralexins were induced by C. zeina in both resistant and susceptible sub-tropical maize lines adapted to the climate of southern Africa [38]. Several candidate genes related to resistance to gibberellic ear rot were found by RNASeq analysis from global gene expression profiles [39]. By combining the RNA-seq and proteome analyses of two maize cultivars, calmodulin-like protein and leucine-rich repeat receptor-like protein kinase, were found to be candidate proteins, potentially linked with resistance to GLS [40]. Although vast progress has been made in the characterization of 
mechanisms underlying the defense against $C$. zeina, the molecular mechanism of maize resistance to GLS remains obscure. Therefore, understanding the responses of maize after C. zeina infection is important in GLS-resistance breeding.

In the present study, based on the response dynamics of PAL, CAT, POD, and FP after C. zeina injection, high-throughput RNA sequencing technology (RNA-Seq) was performed at five representative timepoints on two elite maize inbred lines, R6 and S8, from Southwest China, (previously identified as resistant and susceptible to GLS, respectively). Differentially expressed genes (DEGs) were identified and characterized for function prediction. WGCNA was also analyzed for the construction of a co-expression network and exploitation of the hub genes of the modules related to GLS resistance. Combining these with GLS-resistant QTLs from the previous study, the consensus genes located in the QTL interval were considered candidate genes, which probably play a role in the response to $C$. zeina infection in maize.

\section{Results}

\subsection{Phenotypic Evaluation in Response to C. zeina Infection}

Two inbred maize lines, R6 and S8, were evaluated for quantitative resistance to GLS disease across two environments (Luding and Baoshan) in 2012 and 2013, 15 days after silking. As shown in Figure 1a,b, R6 is significantly resistant to GLS, while S8 is susceptible to GLS. We also assessed the growth status of leaves before and after inoculation with C. zeina at the silking stage in a growth chamber. The gray spots on the leaves of S8 were evident after inoculation compared to the control (Figure 1e,f). In contrast, there were no GLS disease symptoms (except small chlorotic spots) on R6 leaves compared to the control (Figure 1c,d).

a

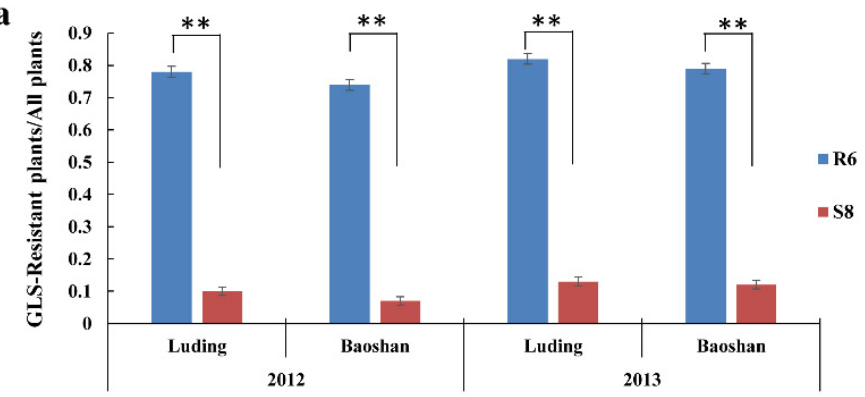

b

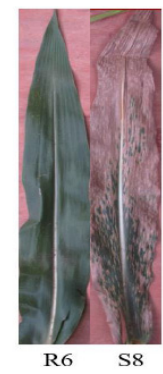

c

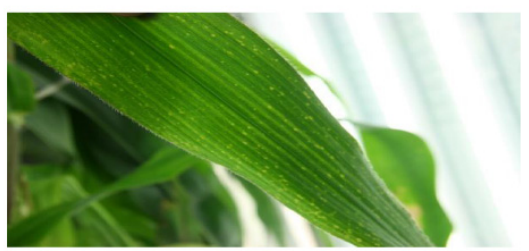

e

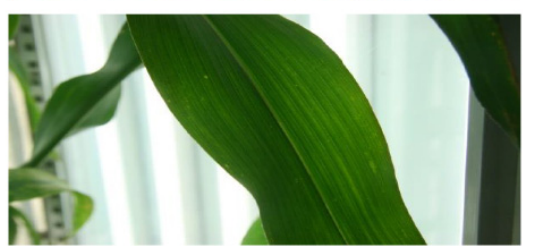

d

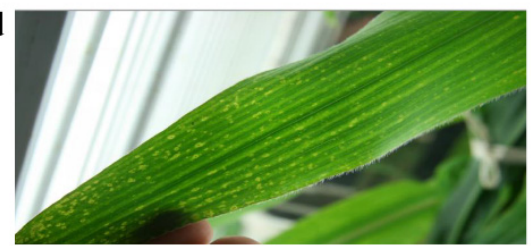

f

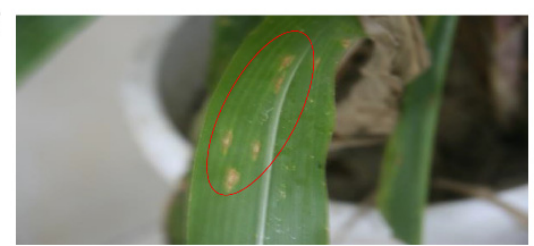

Figure 1. Disease resistance and symptoms of maize inbred lines R6 and S8 in response to C. zeina. (a) The disease resistance, here also known as GLS resistance, was evaluated 15 days after silking. Asterisks indicate significant differences between R6 and S8 (two-tailed Student's t-test; ${ }^{* *}: p<0.01$ ). (b) Leaves of field-grown R6 and S8 infected by C. zeina. (c,d) R6 leaves' performance before (c) and after (d) inoculation with C. zeina; (e,f) S8 leaves before (e) and after (f) inoculation with C. zeina. The infected area is indicated by a red ellipse. 


\subsection{Dynamic Changes of Physiological Characteristics of Maize Leaves in Response to Inoculation C. zeina}

The dynamics of physiological indices can explain the degree of response under abiotic and biotic stresses. To identify potential changes in gene expression in response to inoculation by C. zeina, the activities of PAL, CAT, POD, and contents of FP in maize leaves were analyzed at continuous stages after C. zeina inoculation (Figure 2).
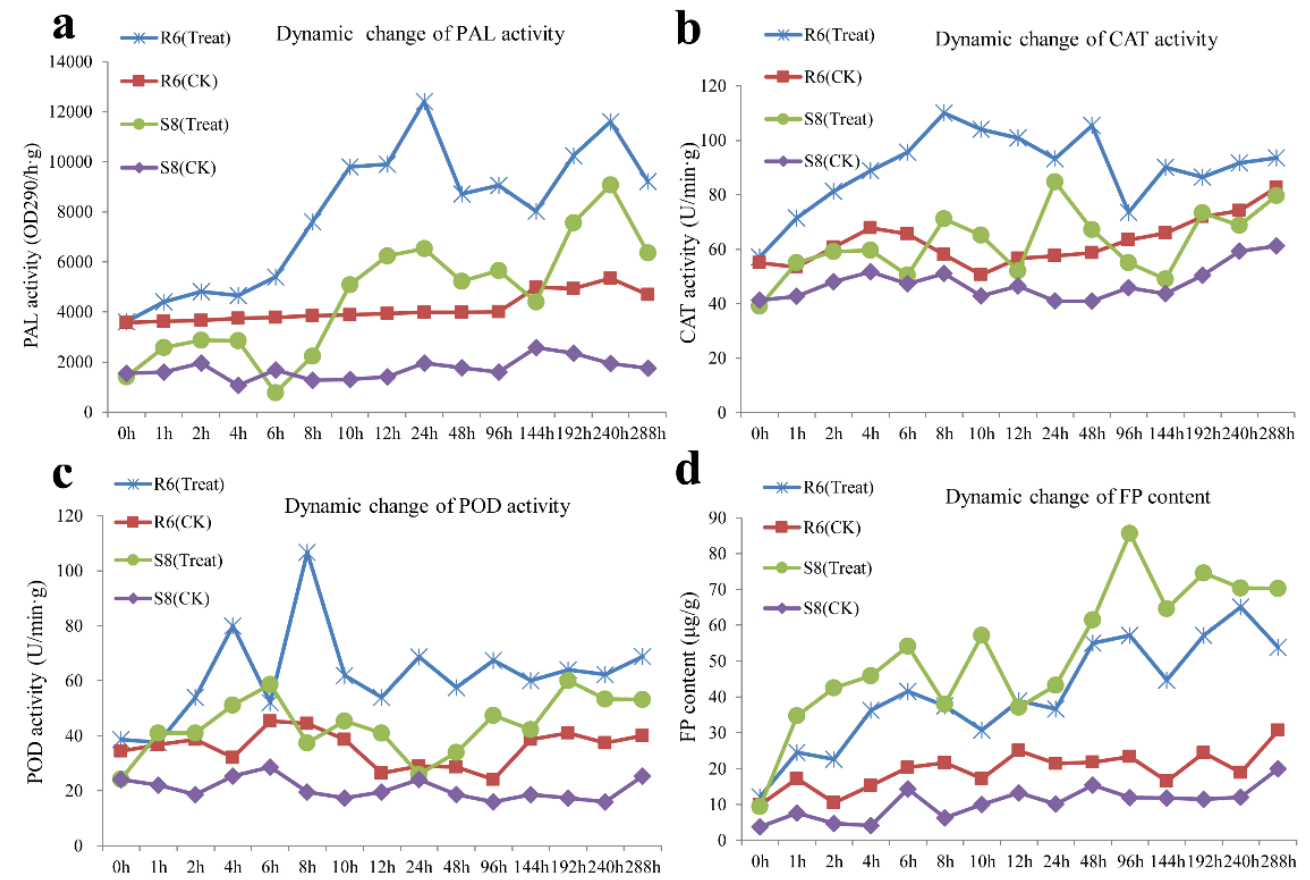

Figure 2. Determination of PAL (a), CAT (b) and POD (c) enzyme activity and FP (d) content in maize leaves in response to $C$. zeina. The $\mathrm{x}$ axis represents infection at different times after inoculation. Maize inbred lines differing in GLS resistance (R6 = resistant and S8 = sensitive) were inoculated with C. zeina (Treat) or not (CK).

As shown in Figure 2a, the PAL, CAT, POD activity and FP content in R6 was always higher than that in S8 at all timepoints. After C. zeina inoculation, the PAL activity in R6 was significantly increased at $6 \mathrm{~h}$, peaked at $24 \mathrm{~h}$, then dropped down. From $144 \mathrm{~h}$ PAL activity recovers, increasing and rising to another peak at $240 \mathrm{~h}$. In S8, the PAL activity was significantly decreased at $6 \mathrm{~h}$ compared to $0 \mathrm{~h}$; afterwards, it showed a similar trend to R6. The changes in CAT activity in S8 were similar to those of PAL activity, which showed significant decreases at $6 \mathrm{~h}, 12 \mathrm{~h}, 144 \mathrm{~h}$, and reached a maximum at $24 \mathrm{~h}$. In R6, from $0 \mathrm{~h}$ to $8 \mathrm{~h}$, the CAT activity was increasing and peaked at $8 \mathrm{~h}$; then, it decreased. After $24 \mathrm{~h}$, activity increased again and reached a peak at $48 \mathrm{~h}$, then significant decreases occurred at $96 \mathrm{~h}$. The CAT activity increased slowly from $144 \mathrm{~h}$ to $288 \mathrm{~h}$ (Figure $2 \mathrm{~b}$ ). The POD activity reached a peak at $8 \mathrm{~h}$ and decreased to its lowest $6 \mathrm{~h}$ after infection in R6; after $12 \mathrm{~h}$, it changed slightly. In treated S8, POD activity showed a significant increase at $6 \mathrm{~h}, 96 \mathrm{~h}$, and $192 \mathrm{~h}$ and a decrease at $8 \mathrm{~h}, 24 \mathrm{~h}$, and $144 \mathrm{~h}$ (Figure 2c). Most interestingly, as shown in Figure 2b, during treatment, the FP content of S8 was higher than in R6 at almost all timepoints, S8 showed four peaks at $6 \mathrm{~h}, 10 \mathrm{~h}, 96 \mathrm{~h}$, and $192 \mathrm{~h}$, then decreased at $8 \mathrm{~h}, 12 \mathrm{~h}$ and $144 \mathrm{~h}$. R6 showed a significant increase at $6 \mathrm{~h}, 12 \mathrm{~h}, 96 \mathrm{~h}$, and $240 \mathrm{~h}$, and a significant decrease at $2 \mathrm{~h}, 10 \mathrm{~h}, 24 \mathrm{~h}$, and $144 \mathrm{~h}$. However, the PAL, CAT, and POD activities were always higher in R6 than S8.

These results implied that the activities of PAL, CAT, POD, as well as FP content, may participate in the response to GLS in maize, with particularly important changes occurring at $6,24,144$, and $240 \mathrm{~h}$ after inoculation. 


\subsection{Profiling the Maize Leaf Transcriptome Responses to C. zeina Infection}

A global gene expression profile of R6 and S8 during C. zeina infection was determined in leaves at $0 \mathrm{~h}, 6 \mathrm{~h}, 24 \mathrm{~h}, 144 \mathrm{~h}$, and $240 \mathrm{~h}$ post-inoculation. After filtering low-quality reads, a total of 550,290,438 clean reads were obtained and mapped to the reference genome B73 RefGen-V3. About 69\% $(381,417,240 / 550,290,438)$ of the reads were mapped to the B73 genome, of which $97 \%(371,518,422 / 381,417,240)$ were uniquely mapped, including 25,264 and 27,529 genes in the two biological replicates (Table S1). FPKM of expression data revealed a high Pearson's correlation between the biological replicates $(>0.86)$ for all the analyzed samples, indicating high reproducibility in the sequencing data (Figure S1).

To characterize the transcriptional changes induced by C. zeina infection in -resistant and -susceptible genotypes, we investigated the DEGs of two inbred lines from multiple timepoints after infection (Figure S2). The FPKMs of genes in two inbred lines were controls for DEG analysis compared with $0 \mathrm{~h}$. Hereafter, the $0 \mathrm{~h}$ of the $\mathrm{S} 8$ sample is named CK1, and the $0 \mathrm{~h}$ of the R6 sample is named CK2. In S8, we identified 3938, 1111, 1388, 1715 DEGs in the four timepoints of $6 \mathrm{~h}, 24 \mathrm{~h}, 144 \mathrm{~h}$, and $240 \mathrm{~h}$, respectively, and 419 DEGs were consistently detected in these four timepoints (Figures 3A and 4). In R6, 5383, 1861, 2790, and 2335 DEGs were identified in the four times of $6 \mathrm{~h}, 24 \mathrm{~h}, 144 \mathrm{~h}$, and $240 \mathrm{~h}$, respectively, with 667 DEGs consistently being detected in all four timepoints (Figures $3 \mathrm{~B}$ and 4). In DEGs detected in all four timepoints (667 in R6 and 419 in S8), we identified 311 DEGs in both R6 and S8, 356 DEGs in R6, and 108 specific DEGs in S8 (Figures 3C and 4, Table S2).

A

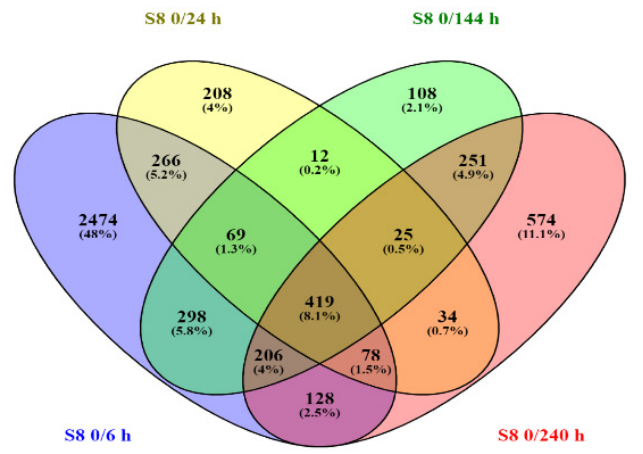

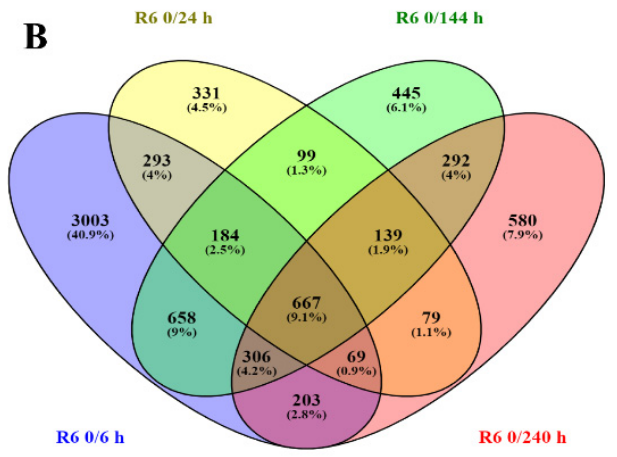

R6

C

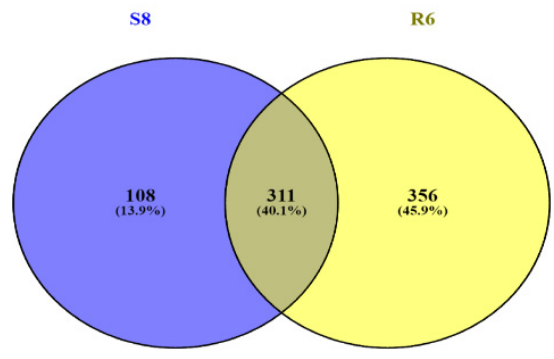

S8 VS R6

Figure 3. Differentially expressed genes in R6 and S8 at various times after inoculation with C. zeina. (A) Venn diagrams of DEGs in the GLS-sensitive line S8; (B) Venn diagrams of DEGs in resistant line R6. (C) Venn diagrams of common DEGs to R6 and S8.

\subsection{Real-Time Quantitative Reverse Transcription-PCR ( $q R T-P C R$ ) Validation}

To evaluate the accuracy of the gene expression level calculated by Illumina RNA-Seq, seven DEGs were randomly selected for the real-time quantitative reverse transcriptionPCR (qRT-PCR), according to their expression patterns at the three selected timepoints. The expression patterns of those seven DEGs showed consistent trends using the two methods (qRT-PCR and RNA-sequencing) (Figure S3), indicating the accuracy of the applied RNAseq analysis for studying C. zeina-infection-induced maize leaf transcriptome. 


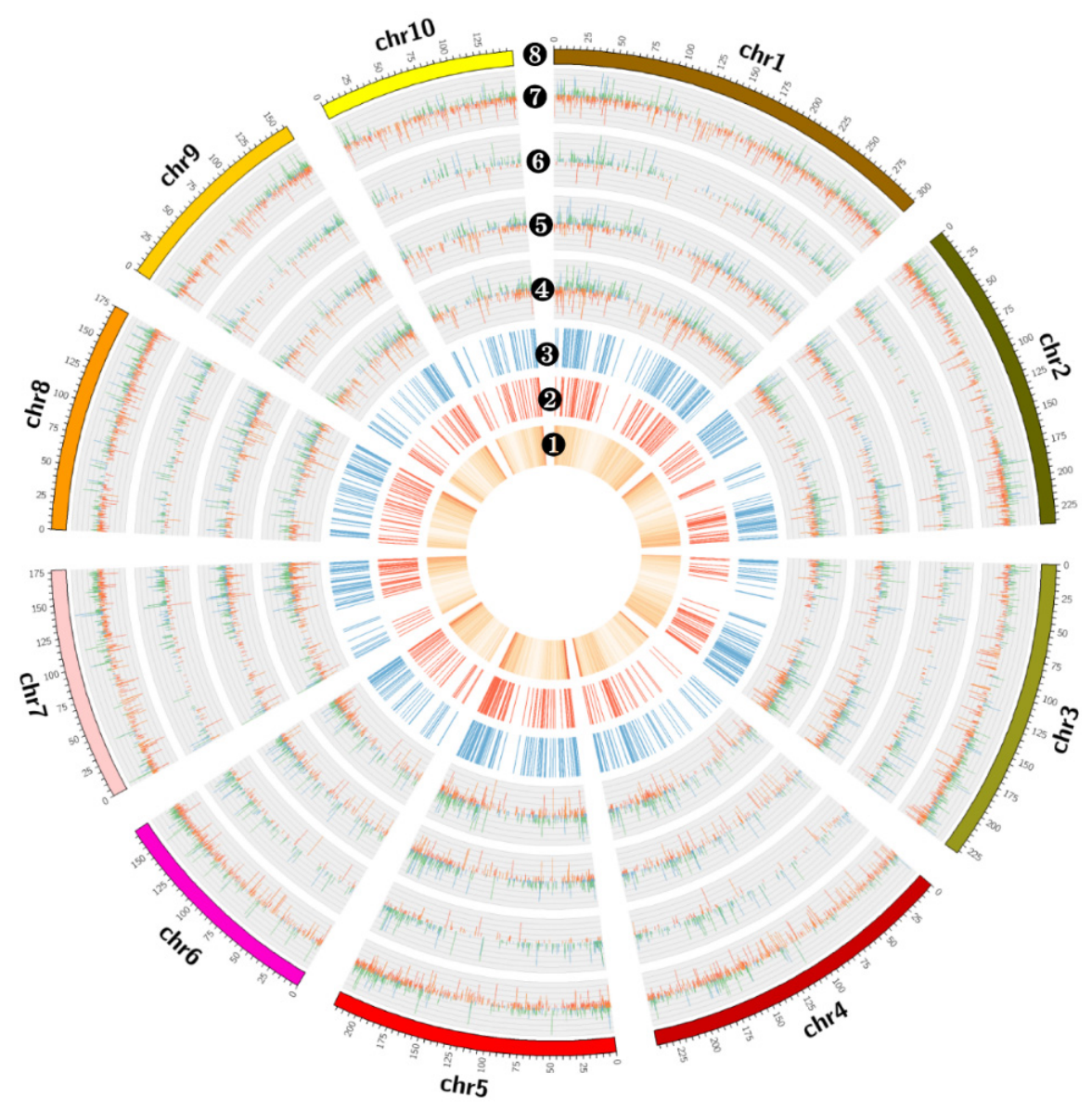

Figure 4. Circular plot of DEG distribution of two inbred lines. The circular plots from the inner to outer layer are Gene frequency in 1-Mb windows of the whole genome, (2) Common DEG frequency in multiple timepoints of $\mathrm{S} 8$ in $1-\mathrm{Mb}$ windows of the whole genome, 3 Common DEG frequency in multiple timepoints of R6 1-Mb windows of the whole genome, 4 log2FC (fold change) of DEGs identified from two inbred lines in 240 h. 5 log2FC of DEGs identified from two inbred lines in $144 \mathrm{~h}$. $\boldsymbol{\theta} \log 2 \mathrm{FC}$ of DEGs identified from two inbred lines in $24 \mathrm{~h} . \boldsymbol{\theta} \log 2 \mathrm{FC}$ of DEGs identified from two inbred lines in $6 \mathrm{~h}$. 8 Chromosome length. In $\mathbf{4 - \boldsymbol { 0 }}$, the red bars are log2FC of up-regulated DEGs from R6, the blue bars are log2FC of downregulated DEGs from R6, the orange bars are log2FC of upregulated DEGs from S8, the green bars are log2FC of downregulated DEGs from S8.

\subsection{Gene Ontology and Pathway Enrichment Analyses of DEGs between R6 and S8}

To characterize the function of the DEGs detected in the two inbred lines, GO term enrichment analysis was performed between R6 and S8 (http:/ / systemsbiology.cau.edu. cn/agriGOv2/index.php, accessed on 15 February 2021) with a threshold of FDR $<0.01$. The 311 overlapped DEGs were enriched in 'response to external stimulus', 'response to biotic stimulus', and 'response to stress', which were closely related to disease resistance (Figure 5a) in the biological process. Both the specific common DEGs of R6 and S8 were enriched in 'response to biotic stimulus', 'response to external stimulus', and 'response to stress' (Figure 5b,c). To understand the specific function of DEGs in each timepoint, specific DEGs were collected at each timepoint for GO analysis. For R6, the GO terms of the biological process were also enriched in 'response to abiotic stimulus', and 'response to stress', which were related to disease resistance (Figure S4). For S8, GO terms of the biological process were enriched in 'response to abiotic stimulus', 'response to stress', 'response to endogenous stimulus', 'response to biotic stimulus', and 'response to external stimulus' (Figure S5). Due to the resistance variance between R6 and S8, we also compared the GO terms at each timepoint between the two inbred lines. It was worth noting that, at four timepoints, specific DEGs of two inbred lines were both enriched in 'response to 
stimulus', and 'response to biotic stimulus' in the biological process (Figures S6 and S7), while more GO terms related to reproduction and development were found. This indicated that R6 might maintain the development and reproduction process after C. zeina infection. This could be a factor in R6's increased resistance to gray leaf spot disease.

a

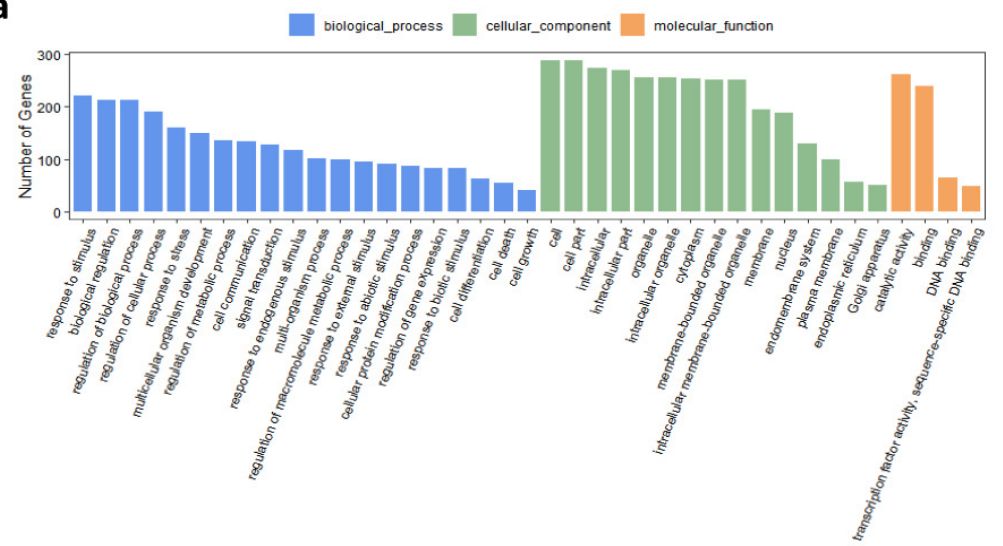

b

GO term

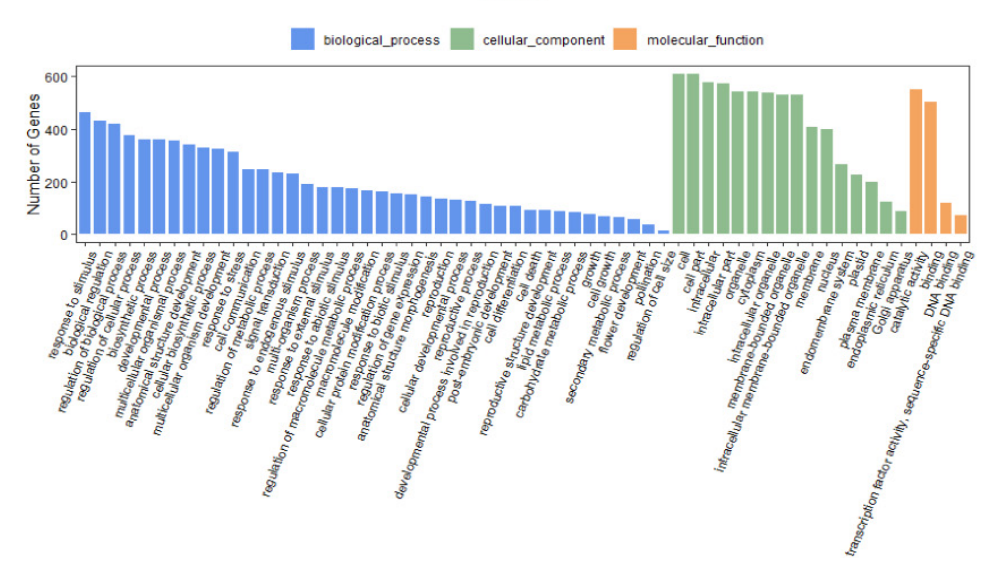

GO term

c

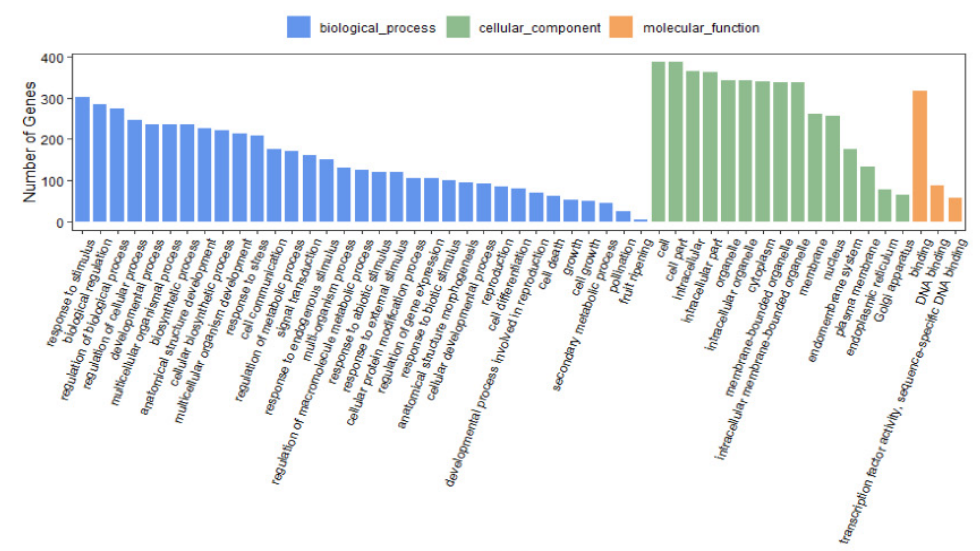

GO term

Figure 5. GO term enrichment of common DEGs from R6 and S8 at multiple timepoints. (a) GO term enrichment of overlap common DEGs between R6 and S8. (b) GO term enrichment of specific common DEGs from R6. (c) GO term enrichment of specific common DEGs from S8.

The KEGG pathway analysis (http://kobas.cbi.pku.edu.cn/kobas3/genelist/, accessed on 15 February 2021) was used to elucidate the biological function of specific DEGs with a corrected $p$-valve $<0.05$. The 311 common DEGs described above were enriched in 'plant-pathogen interaction', 'plant hormone signal transduction', and 'MAPK signaling 
pathway-plant' (Figure 6a). The 356 specific DEGs of R6 were enriched in 'plant-pathogen interaction', 'plant hormone signal transduction', 'MAPK signaling pathway-plant', and 'benzoxazinoid biosynthesis' (Figure 6b), while 108 specific DEGs of S8 were not enriched in any pathways. The common DEGs of R6 participated in 'plant-pathogen interaction', 'MAPK signaling pathway—plant', 'plant hormone signal transduction', and 'amino sugar and nucleotide sugar metabolism', which were closely related to disease resistance, at multiple timepoints. The common DEGs of S8 participated in the same pathways, except for 'amino sugar and nucleotide sugar metabolism' (Figure S8a). To dissect the gene coexpression at each time point, we extracted specific DEGs and investigated the pathway enrichment for each timepoint. Combing the enriched pathways, analyzed at multiple timepoints, those of R6 were enriched regarding 'plant-pathogen interaction' and 'plant hormone signal transduction' pathways (Figure S8b), while the DEGs of S8 were enriched in 'plant-pathogen interaction' and 'monoterpenoid biosynthesis' pathways (Figure S8c). These results indicated that DEGs played an essential role in the regulation of hormones or metabolites for disease resistance. To study the difference in resistance, we also investigated KEGG pathway enrichment between two inbred lines. The KEGG pathways of common DEGs from R6 and S8 were enriched at multiple timepoints in 'metabolic pathways' and 'biosynthesis of secondary metabolites' (Figure S9a). The specific DEGs of R6 and S8 at these timepoints were enriched in 'metabolic pathways', and 'biosynthesis of secondary metabolites' (Figure S9b,c). These results suggested that the biosynthesis of secondary metabolic pathways was important in the gray leaf spot response, while the DEGs of R6 enriched more pathways than those of S8, including amino acid, starch and sucrose, and hormone biosynthesis.

a

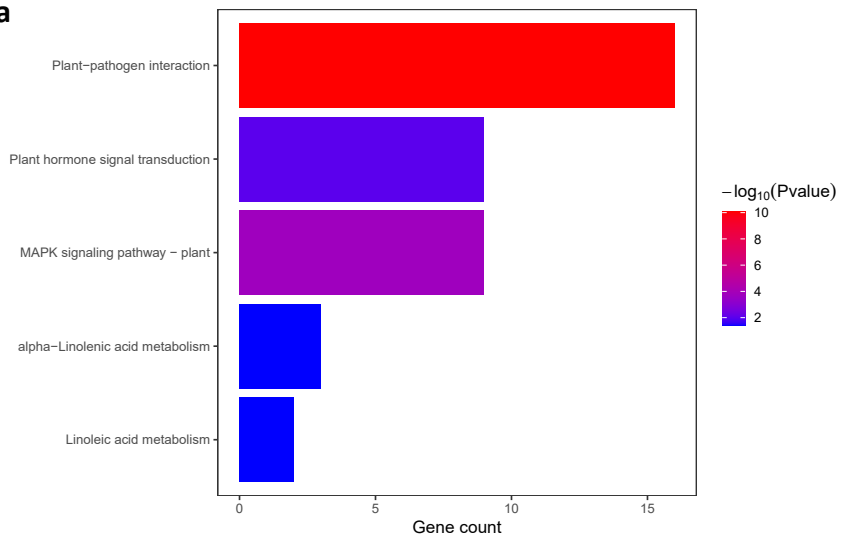

b

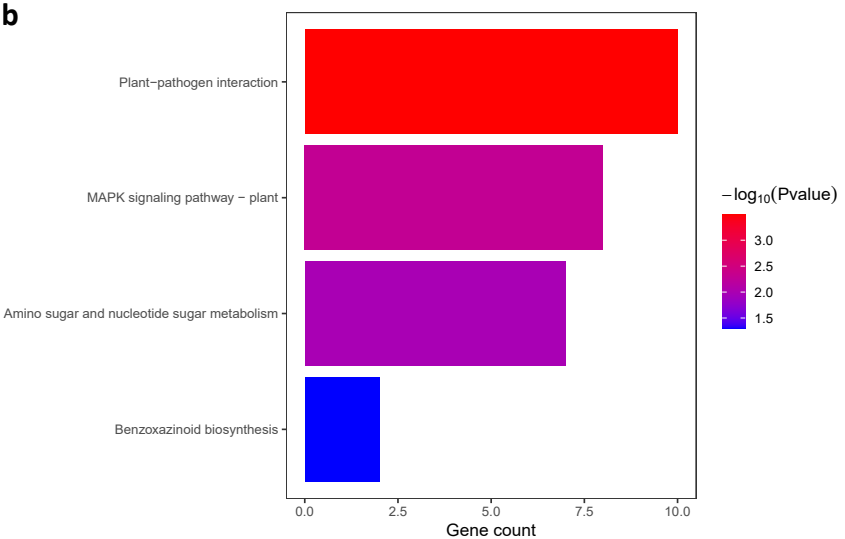

Figure 6. KEGG pathway enrichment of common DEGs from R6 and S8 at multiple timepoints. (a) KEGG pathway enrichment of overlap common DEGs between R6 and S8. (b) KEGG pathway enrichment of specific common DEGs from R6.

\subsection{Co-Expression Network of Genes Related to C. zeina Resistance}

To investigate the gene regulation related to gray leaf spot resistance, a total of 18,873 highly expressed genes were collected for WGCNA analysis. The sample cluster diagram showed that no outliers were detected in our transcriptomes (Figure S10). To construct the scale-free network, the weighted value was set as 12 for the adjacent matrix, according to the soft threshold of scale-free topology (Figure S11a,b). The dynamic tree cut method was used for gene module division, setting the gene number threshold as 30, and the similar expression pattern was merged by an eigenvalue distance of less than 0.2 (Figure 7). Different color bars represent different gene modules, and the gray bar means the module cannot be merged into other modules. Overall, 45 modules, containing from 41 to 1668 genes, were obtained in our study (Table S3). Among these, the Black module contained the most genes, while the Lightpink2 module contained the fewest genes. Moreover, most modules contained no DEGs, although Grey60 contained 445 DEGs, which was the highest number of DEGs (Table S3). The correlation between modules and traits demonstrated 
that six modules showed high correlation. The correlation coefficients of Purple and CK1, Thistle1 and S8-240h, Greenyellow and R6-6h, Orange and S8-6h, Magenta and R6-6h, Grey60 and CK2 were higher than 0.80 (Figure S12). To investigate the modules related to disease resistance, GO-term enrichment analysis was performed for the genes in each module. The results indicated 13 modules, including Black, Darkmagenta, Darkolivegreen, Darkolivegreen4, Greenyellow, Grey60, Lightpink2, Magenta, Magenta4, Mediumpurple4, Palevioletred2, Purple, and Yellowgreen, were related to disease resistance. These were the GO terms for BP enrichment in 'response to abiotic stimulus', 'response to stress', and 'response to endogenous stimulus' (Table S4). KEGG pathway enrichment was also analyzed for all the modules. The results showed that an essential pathway, 'plant-pathogen interaction', was enriched in Grey60 and Purple modules (Table S5). The hub genes were all DEGs, determined as the top ten genes for connectivity in each module. These hub genes were extracted for the construction of the co-expression network (Figure 8, Table S6). It is worth noting that some of the hub genes showed a close relationship to disease resistance. For example, GRMZM2G027499 was a homolog of ENHANCED DISEASE RESISTANCE4 (EDR4) in sorghum and Arabidopsis, which plays an important role in resistance to powdery mildew, was required by salicylic acid signaling [41]. GRMZM2G055052, encoding a RING-type E3 ubiquitin transferase, and its homologous gene, was shown to function in the immune response pathway by targeting BIK1 for degradation [42]. The homologous gene PBL13 of GRMZM2G057779 was a Serine/Threonine Protein kinase that negatively regulates immune responses in Arabidopsis [43]. GRMZM2G121565 encodes a Putative inactive leucine-rich repeat receptor-like protein kinase; the homolog of this gene modulates brassinosteroid signaling [44], and is required for innate immunity to hemibiotrophic and biotrophic pathogens [45]. GRMZM2G016264 and GRMZM2G159179 both encode putative cytochrome P450 superfamily protein; the homolog CYP94C1 catalyzes the oxidation steps of hormone jasmonoyl-isoleucine and participates in the jasmonate hormonal pathway, which is important for plant defense and development [46]. GRMZM2G167492 encodes putative NAC domain transcription factor NACTF97, contributing to the oxidative stress response, as well as participating in the regulation of plant development and the abiotic stress response [47]. GRMZM2G467184 encodes a putative calcium-binding protein; a similar protein in wheat has been validated to confer resistance to Fusarium head blight [48]. In summary, the predicted function of hub genes demonstrated that hormone signaling, calcium signaling pathways, and transcription factors played a central role in GLS resistance.

\subsection{Identified Resistance-Related Genes Response to C. zeina from DEGs}

To identify disease-resistance-related genes after C. zeina infection according to the transcriptional level, a total of fifty-three putative defense response genes were identified between the R6 and S8. The contents of sixteen Leucine-rich repeat (LRR) or similar genes that were close homologs of flagellin sensing 2 (FLS2) and EF-Tu receptor (EFR), three MAPK or $M A P K$-like genes, five ETI-related genes, four plant-hormone-related genes, and twentyfour other defense-related genes that were differentially expressed between R6 and S8 were analyzed (Figure 9, Table S7).

The transcripts of the two RPP genes (XLOC_021615 and XLOC_021616), one RPM1-like gene (XLOC_042398), two LRR or similar genes (GRMZM2G171114 and GRMZM2G702599), MAPK gene (GRMZM2G375975), and MYC2 (XLOC_021916) were specifically expressed in the GLS-resistant line R6 (Figure 9, Table S6). Other defense-related genes, such as the PEN1 gene (GRMZM2G044527), TGA gene, and PEN2-like genes (GRMZM2G146192 and GRMZM2G008247) were highly expressed in the GLS-resistant line (R6) (Figure 9, Table S6).

\subsection{Integration of QTL Mapping and DEGs to Find the Candidate Genes' Response to C. zeina}

In previous QTL-mapping, four GLS-resistance QTLs ( $q$ Rgls.CH-1, $q$ Rgls.CH-2, qRgls.CH-4, and qRgls.CH-6) were identified in different chromosomes [49]. Candidate DEGs identified 
from RNA-seq that were consistently located in the QTL interval were considered consensus genes, which were more reliable for further analysis. Using the physical location of QTL (Table S8), four genes (GRMZM2G702599, GRMZM2G447795, GRMZM2G171114, and GRMZM2G135108) from fifty-three putative defense genes and one gene (GRMZM2G044537) from twenty DEG hub genes (Table S6, S7 and S9) were mapped within the previous QTL regions. Interestingly, GRMZM2G702599 and GRMZM2G171114 were specifically expressed in R6 (Figure 9, Table S7), and were both putative Leucine-rich repeat protein kinase family proteins, which are highly likely to be resist to GLS. Moreover, another three genes located in QTL regions, i.e., GRMZM2G044537, which was putative RING zinc finger protein-like, GRMZM2G447795, which was putative Xylanase inhibitor protein 1, and GRMZM2G135108, which was putative Peroxidase, are worthy of note as well.

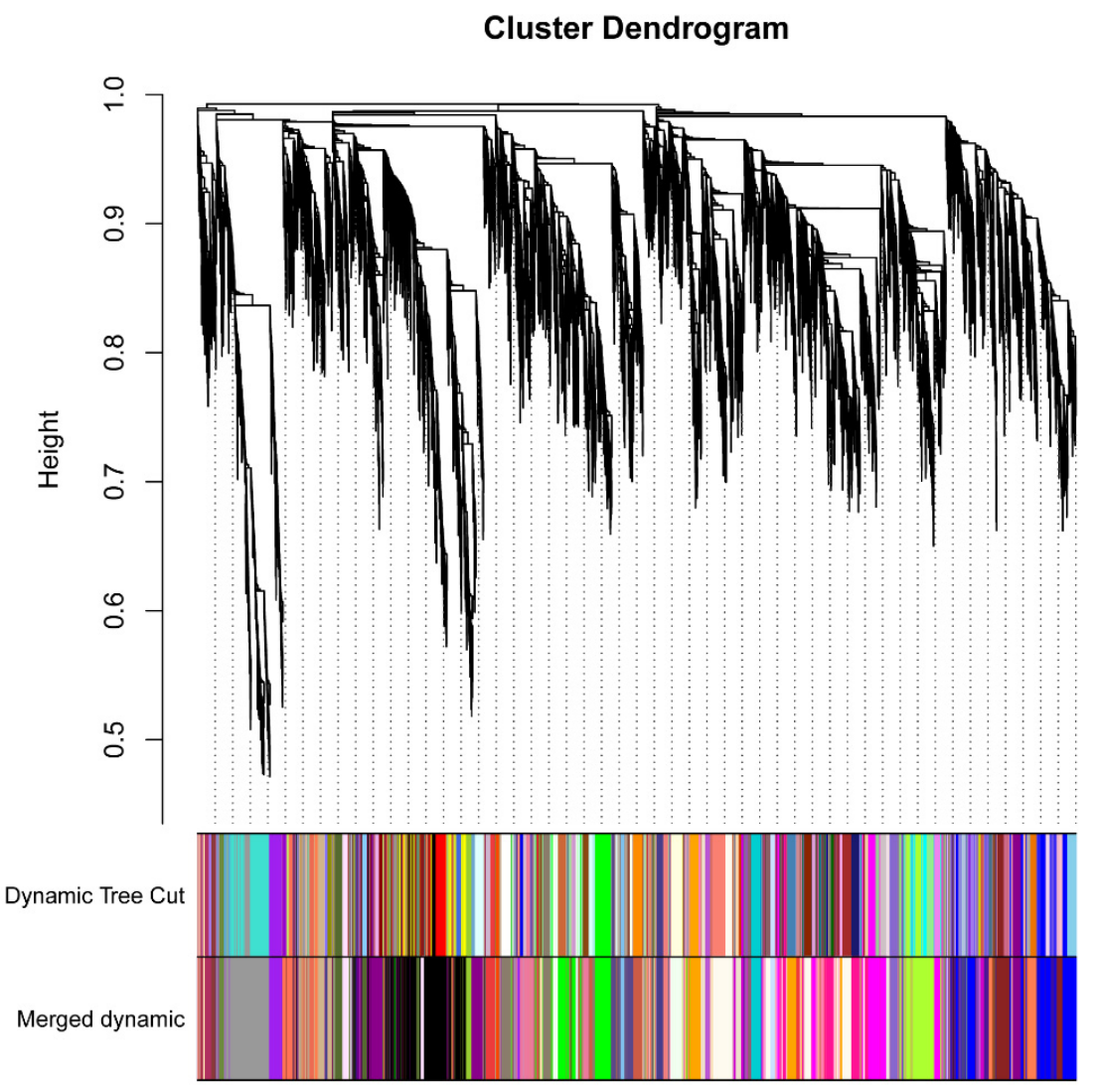

Figure 7. Gene cluster dendrograms and module detection. From the top to the bottom are clustering dendrograms of genes based on the topological overlap, gene modules of dynamic tree cut, gene modules of merged dynamic tree cut, created by merging similar modules.
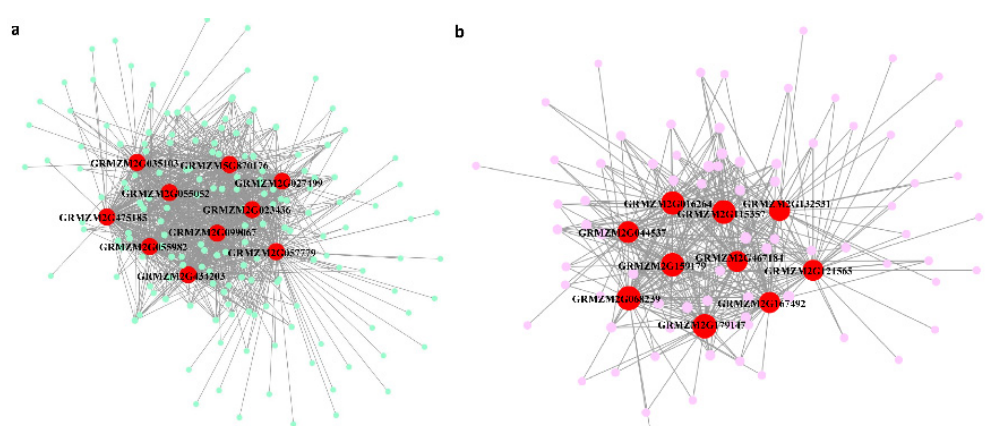

Figure 8. Co-expression network of related gene modules grey60 (a) and purple (b). Only hub genes from two modules were exhibited in the network. 


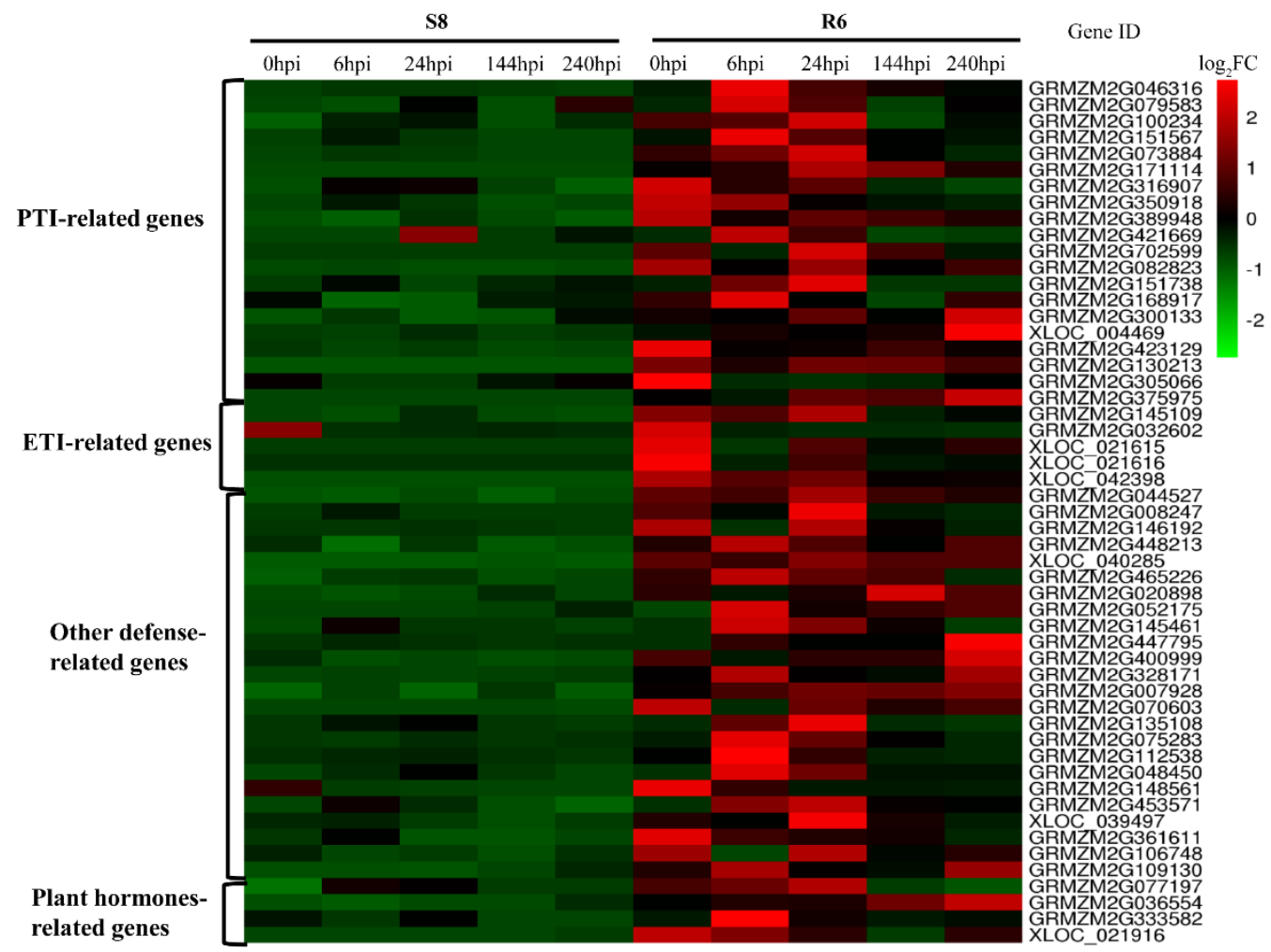

Figure 9. Heat maps of gene transcripts in GLS-sensitive (S8) and GLS-resistant (R6) lines after C. zeina infection $[p<0.001$ and $\log 2 \mathrm{FC}$ (fold change) $>1.0$ or $<-1.0]$. The PTI-, ETI-, defense-related, and hormone-related genes whose expression differed significantly are shown. Red indicates higher transcript levels.

\section{Discussion}

Since the maize defense mechanism against $C$. zeina is far too unraveled to date, we first compared the physiological characterization of key enzymes related to plant defence. According to the intensity of response, timepoints were chosen to compare the specific transcriptome profiling of two inbred maize lines that differed in GLS resistance after $C$. zeina infection. After QTL mapping and WGCNA analysis, many candidate genes were identified, which provided important information regarding their mechanism of resistance against GLS.

In our study, the PAL, CAT and POD of the resistant line R6 showed higher activity than the susceptible line S8. Although both the resistant and susceptible lines showed an intense response after C. zeina infection at different timepoints, the resistant line, R6, was more dramatically changed compared with the susceptible line, S8, except for FP content. These results suggest that the different resistance levels of R6 and S8 may be related to two physiological mechanisms. One is the initial activity or content: the resistant lines, R6, always showed higher activity or content than the susceptible line S8; the higher activity or content of enzymes led to a superior defense when C. zeina invaded maize leaves. The other is the intensity of activity changes after $C$. zeina infection. Higher intensity implies a stronger defense, with a higher accumulation of phenylpropanoid pathway products, and stronger hydrogen peroxide degradation. The PAL, CAT, and POD might be applicable physiological signs when screening the response of resistant inbred lines to GLS when infected by C. zeina.

According to the PAL, CAT, POD, and FP response to C. zeina infection in maize leaves, five stages $(0,6,24,144$, and $240 \mathrm{~h})$ were chosen to investigate the transcriptional changes that occurred in response to C. zeina infection in more detail. The GO term showed that the DEGs were significantly enriched in defense responses such as 'response to biotic stimulus' and 'response to stress', and the KEGG pathway was correspondingly enriched 
in its 'plant-pathogen interaction', 'MAPK signaling pathway-plant', and 'plant hormone signal transduction', which indicated that the MAPK signaling pathway and hormone signal transduction were essential after C. zeina infection. Some studies have shown that MAPK cascades play pivotal roles in plant defense against pathogen attack and are the earliest signaling events after sensing the pathogen [50]. The plant hormone crosstalk can potentially enhance pathogen resistance and overall plant fitness [51]. It is notable that 'Benzoxazinoid biosynthesis' is a specific pathway enriched in R6. The pathway participates in the regulation of innate immunity against aphids and fungi in maize [52], which may contribute to the superior resistance of R6.

The specific interactions between plant and pathogen can be addressed by identifying the transcription alterations in critical genes involved in PTI and ETI, such as pathogenassociated molecular pattern (PAMP) receptors (PRRs), ETI receptors, salicylic acid (SA)-, jasmonic acid (JA)-, and ethylene (ET)-response genes [25,53-56]. Two EFR- and FLS2-like genes, as the putative PAMP receptors, were expressed only in R6. Importantly, the key PTI genes triggered by PAMPs, such as MAPK genes, were highly expressed in the GLSresistant line at all timepoints, and one MAPK gene (GRMZM2G375975) was specifically expressed in R6 (Figure 9; Table S6). Genes expressed in the early-stage responses, such as 0 and $6 \mathrm{~h}$, might be more important for GLS resistance than those expressed at the later stages (i.e., 24, 144, and $240 \mathrm{~h}$ ). In this study, the transcripts of the two RPP genes (XLOC_021615 and XLOC_021616) were specifically expressed in the GLS-resistant line. It was validated that the RPP genes trigger localized cell death in Arabidopsis upon recognition of downy mildew avirulence genes [57]. In Arabidopsis, RPM1 encodes an intracellular immune sensor that is induced in response to Pseudomonas syringae, and attack by this pathogen leads to the expression of RPM1 disease resistance genes [58,59]. In the present study, one RPM1-like gene (XLOC_042398) was specifically expressed in the GLS-resistant line R6. PENETRATION 1 (PEN1), PEN2, and PEN3 have been demonstrated to play an essential role in non-host resistance [54]. One PEN1 gene (GRMZM2G044527), two PEN2-like genes (GRMZM2G146192 and GRMZM2G008247) were up-regulated in the GLS-resistant line at all timepoints (Figure 9, Table S6). WRKY TFs have also been shown to be involved in plant immune responses to bacterial pathogens [60]. The LOX1mediated pathways are crucial for lipid peroxidation during plant defense responses to pathogen infection [61]. The transcript levels of two LOX1 (GRMZM2G106748 and GRMZM2G109130) genes were low at all sample timepoints in the GLS-susceptible line S8 (Figure 9, Table S6). In contrast, these defense-related genes were highly expressed in the GLS-resistant line (R6). JA/ET primarily participates in the deterrence of herbivores and resistance to necrotrophic pathogens, whereas SA is primarily involved in resistance to biotrophic and hemibiotrophic pathogens [62]. The expression of a maize non-expressor of the PR1 gene [NPR1-like gene (GRMZM2G077197)] was higher in terms of resistance than the sensitive line at 0, 6, and $24 \mathrm{~h}$ (Figure 9, Table S6); NPR1 is an important regulatory component in the SA signaling. The core JA-signaling component MYC2 had a significantly higher resistance than the sensitive line all the time; hence, upregulation of $M Y C 2$ related to JA-signaling was shown in the GLS-resistant line. One reason for the elevated expression of JA signaling components may be that the leaf scrubbing before spraying C. zeina spore suspension was perceived as wounding. Alternatively, endogenous levels of JA may be elevated in the GLS-resistant line compared with the GLS-susceptible line.

GLS is a severe disease, resulting in an extreme reduction in the grain yield of maize. In our study, the transcriptomic atlases at different timepoints were analyzed for the DEGs identified after C. zeina infection. Combining QTL mapping and WGCNA, we analyzed candidate genes, the homolog of which was related to immune response and disease resistance. Other than the single functional genes, transcription factors such as MYBs, and hormone-related genes, such as JA and ethylene-related genes, were involved in GLS response and resistance. These results indicated the complex defense mechanisms against GLS and provided gene resources for further validation. 


\section{Materials and Methods}

\subsection{Plant Materials and Disease Resistance Scoring}

The inbred maize lines 646 (resistant line, named R6) and 08-641 (susceptible line, named S8) were used in the current study. R6 was developed at WUGU Seed Company Limited with stable GLS resistance, whereas S8 is a GLS-susceptible inbred line developed at the Maize Research Institute of Sichuan Agricultural University. The GLS resistance of the two maize inbred lines was evaluated across Luding and Baoshan (Sichuan and Yunnan Province, China) in 2012 and 2013, respectively. Three replicates were set for each genotype, with more than 200 plants per replicate. All the plants were scored for GLS with 10-day intervals, starting 15 days after silking. The GLS rating ranged from 1 to 9 , with 1 and 3 being considered resistant, 5, 7, and 9 representing susceptibility [63].

\subsection{The C. zeina Strain Preparation and Inoculation}

C. zeina, used as inoculum, was collected from fresh leaves infected by C. zeina in Luding, Sichuan Province, an area with natural and heavy gray leaf spot infection. The fungal spores were collected by washing leaves infected by C. zeina, and the suspension was concentrated. The spore suspensions used for inoculation were adjusted to a density of $200 \times 104$ spores per $\mathrm{mL}$ using a hemocytometer.

All sample plants were scrubbed with emery (600 mesh) and then inoculated at the flowering stage by spraying a suspension of spores (approximately $3-5 \mathrm{~mL}$ per plant, on 3 consecutive days) on the leaf surface of each plant; the relative humidity of the growth chamber and temperature were adjusted to $100 \%$ and $25{ }^{\circ} \mathrm{C}$ (high humidity and mild temperature) to ensure the occurrence of GLS.

\subsection{Antioxidant Enzymes Activity and Proline Assay}

After inoculation, maize leaves of each genotype were collected at 0 (control: the spore suspension sprayed and then sampled immediately), 1, 2, 4, 6, 8, 10, 12, 24, 48, 96, 144, 192, $240,288 \mathrm{~h}$ post-inoculation. All the samples were immediately frozen in liquid nitrogen and stored at $-80^{\circ} \mathrm{C}$.

Leaf materials with fresh weights of $1 \mathrm{~g}$ were homogenized in phosphate saline buffer ( $\mathrm{pH} 7.8,0.05 \mathrm{M})$ containing $\beta$-mercaptoethanol $(2 \mu \mathrm{L})$ and a trace of polyvinylpyrrolidone (PVP). The homogenate was filtered through cheesecloth and centrifuged at $12,000 \times g$ at $-4{ }^{\circ} \mathrm{C}$ for $10 \mathrm{~min}$, and the supernatant was collected for enzyme activity assay.

The PAL activity assay used the method described by Wang et al. [64]. One unit of the enzyme was defined as an increase in absorbance of one unit per min. The enzyme activity was expressed as units per $\mathrm{mg}$ of soluble protein.

The CAT activity was assayed by measuring the initial rate of $\mathrm{H}_{2} \mathrm{O}_{2}$ disappearance using the method of Beers and Sizer [65]. The catalase assay reaction mixture contained $0.05 \mathrm{mM}$ sodium phosphate buffer ( $\mathrm{pH}$ 7.0), $20 \mu \mathrm{L}$ enzyme extract $/ \mathrm{mL}$ and $1 \mathrm{mM} \mathrm{H}_{2} \mathrm{O}_{2}$. Degradation of $\mathrm{H}_{2} \mathrm{O}_{2}$ was followed by measuring a decrease in absorbance at $240 \mathrm{~nm}$, and the activity [ $\mathrm{U}$ (mg protein) ${ }^{-1}$ ] was calculated using a molar absorption coefficient of $40 \mathrm{mM}^{-1} \mathrm{~cm}^{-1}$ for $\mathrm{H}_{2} \mathrm{O}_{2}$.

The peroxidase (POD) activity was determined using the method of Upadhyaya et al. [66] in a $3.9 \mathrm{~mL}$ reaction mixture containing $50 \mathrm{mM}$ phosphate buffer ( $\mathrm{pH}$ 7.0), $28 \mathrm{~mL}$ of guaiacol, $100 \mu \mathrm{L}$ enzyme extract, and $19 \mu \mathrm{L} \mathrm{H}_{2} \mathrm{O}_{2}$. The absorbance was monitored at $420 \mathrm{~nm}$ for at least $2 \mathrm{~min}$ at $30 \mathrm{~s}$ intervals; absorbance changes of 0.01 represented one unit of POD activity.

The FP was analyzed according to the method of Bates et al. [67]. The chromophore containing the FP was aspirated and added to a test tube, then warmed to room temperature, and the absorbance was measured at $520 \mathrm{~nm}$ on a spectrophotometer (Hitachi U-2001, Japan). A standard curve was constructed by running the proline standards. All assays were conducted for three biological replicates for each treatment. 


\subsection{Samples Collection and RNA Isolation}

Based on the antioxidant enzyme activity assay results, the leaf samples were collected at $0,6,24,144$, and $240 \mathrm{~h}$ from inoculated and control plants to obtain the enriched expression library. Total RNA was extracted using Trizol reagent (Invitrogen, Carlsbad, CA, USA) according to the manufacturer's instructions, and mRNA was enriched by Oligo (dT) beads. The enriched mRNA was fragmented and reverse-transcribed into cDNA with random primers. Second-strand cDNAs were synthesized by DNA polymerase I, RNase $\mathrm{H}$, $\mathrm{dNTP}$, and buffer. The cDNA fragments were purified using a QiaQuick PCR extraction kit, end-repaired, poly (A)-supplemented, and ligated to Illumina sequencing adapters. Two independent biological replicates were used for RNA-seq experiments.

\subsection{RNA Sequencing and Data Analysis}

RNA library sequencing was performed using an Illumina HiSeqTM 2500 by Gene Denovo Biotechnology Co. (Guangzhou, China). Raw reads were filtered by removing reads with adaptor sequences, reads in which the percentage of unknown bases $(\mathrm{N})$ was greater than $10 \%$, and low-quality reads. Clean reads were used for mapping, calculation, and normalization of gene expression. All the clean reads in each sample were mapped to B73 (RefGen_V3) genomic DNA sequence using Tophat2 (2.1.1) [68]. Gene abundances were quantified by software RSEM (v1.3.1) [69]. edgeR package (version 3.22.5) (http: / / www.r-project.org/, accessed on 15 February 2021) was used to identify differentially expressed genes among the samples [70]. We identified genes with a fold change $\geq 2$ and a false discovery rate (FDR) $<0.05$ in a comparison as significant DEGs. All DEGs were mapped to GO terms in the Gene Ontology database (http:/ / www.geneontology.org/, accessed on 15 February 2021); the gene numbers were calculated for every term, and significantly enriched GO terms in DEGs, in comparison with the genome background, were defined by hypergeometric test. The calculated $p$ values were subjected to FDR correction, taking FDR $\leq 0.05$ as a threshold.

\subsection{Validation of RNA-Seq Results by $q R T-P C R$}

Quantitative real-time PCR was used to validate the DEGs between the resistant and susceptible genotypes. RNA extraction and first-strand cDNAs synthesis were carried out as described above. Actin1 (GRMZM2G126010) was used as the endogenous control. The corresponding primers were designed using Primer 5 software and are listed in Table S10. Each $16 \mu \mathrm{L}$ PCR mixture contained $8 \mu \mathrm{L}$ of $2 \times$ real-time SYBR Green I PCR Mix, $0.2 \mu \mathrm{L}$ of each primer, and an appropriate quantity of cDNA. The amplification programs were set according to the standard $\mathrm{ABI}$ ViiA ${ }^{\mathrm{TM}} 7$ system protocol: $95^{\circ} \mathrm{C}$ for $2 \mathrm{~min}$; followed by 40 cycles of $94^{\circ} \mathrm{C}$ for $10 \mathrm{~s}, 60^{\circ} \mathrm{C}$ for $10 \mathrm{~s}$ and $72{ }^{\circ} \mathrm{C}$ for $40 \mathrm{~s}$. The threshold cycles (Ct) of each tested gene were averaged for triplicate reactions, and the values were normalized according to the $\mathrm{Ct}$ of the control products of the Actin1 gene. The statistical analysis was performed using the $2^{-\Delta \Delta C T}$ method [71].

\subsection{WGCNA Analysis of RNA-Seq Data from Multiple Timepoints}

The RNA-Seq data including two biological repeats were collected for WGCNA analysis. The genes with low FPKM $(<5)$ at all timepoints were filtered because they were not meaningful for downstream analysis. The correlation coefficient between each pair of genes was calculated by the formula: $\mathrm{Smn}=\operatorname{cor}(\mathrm{xm}, \mathrm{xn}), \mathrm{S}=[\mathrm{Smn}]$; the Smn represented the Pearson correlation coefficient between gene $\mathrm{m}$ and gene $\mathrm{n}$, while $\mathrm{S}$ represented similar matrix. WGCNA R package (version 1.6.9) was used for WGCNA analysis [72]. To make the network conform to the scale-free network distribution, the suitable weighted value was estimated by the function 'pickSoftThreshold' of WGCNA according to a threshold of 0.8 . The topological overlap matrix (TOM) was transformed from the adjacent matrix. Inverse matrix was calculated by TOM, and use 'hclust' to perform hierarchical clustering. The cluster tree was cut by Dynamic Tree Cut, and the gene cutoff in each module was set to 30 . The modules with a similar expression pattern $(>0.8)$ were merged as the final coexpression 
module. GO term and KEGG pathway enrichment were performed for each module, and modules were extracted for the hub gene screen according to the result. The hub genes were screened as the common DEGs from the top ten genes in terms of connectivity in the related modules. The coexpression network of hub genes was constructed by Cytoscape 3.8.1 [73].

\section{Conclusions}

By using RNA-Seq to characterize the differential expression of genes over five disease stages caused by C. zeina, a genome-wide transcription profile of disease development in maize was obtained. Combined with the QTL, five genes were identified as candidate genes for GLS resistance. The molecular functions of these genes and their associated pathways provided insights into the molecular mechanisms of the GLS development in maize in response to $C$. zeina infection. These results will facilitate future analyses of the resistance mechanism and will contribute to breeding maize that is resistant to gray leaf spot.

Supplementary Materials: The following are available online at https:/ / www.mdpi.com/article / 10.3390 / plants10112257/s1, Figure S1: Correlation tests for the replicates. The $\mathrm{x}$ and $\mathrm{y}$ axis feature FPKM in each replicate. R2 is the square of Pearson's correlation coefficient. Note: CK $=0 \mathrm{~h} ; 6 \mathrm{~h}=6 \mathrm{~h}$; $1 \mathrm{~d}=24 \mathrm{~h} ; 6 \mathrm{~d}=144 \mathrm{~h} ; 10 \mathrm{~d}=240 \mathrm{~h}$. Figure S2: Volcano plot of DEGs between maize lines R6 and S8 at various times after inoculation with C. zeina. The Log2FC (fold change) in red represents significantly upregulated and green shows significantly downregulated transcripts (FDR < 0.05). Figure S3: Verification of RNA-seq results by qRT-PCR. The Y axis (left) indicates the results of qRT-PCR, and the $\mathrm{Y}$ axis (right) indicates the results of transcriptome; the $\mathrm{X}$-axis indicates the sample time, CK: control, 6 hpi: $6 \mathrm{~h}$ post-inoculation, $24 \mathrm{hpi}$ : $24 \mathrm{~h}$ post-inoculation. S8: GLS-sensitive line, R6: GLS-resistant line. Figure S4: GO term enrichment of DEGs from R6 at different timepoints. (a-d) GO term enrichment of DEGs from 6 h, 24 h, 144 h, and 240 h. Figure S5: GO term enrichment of DEGs from S8 at different timepoints. $(\mathrm{a}-\mathrm{c}) \mathrm{GO}$ term enrichment of DEGs from $6 \mathrm{~h}, 24 \mathrm{~h}$, and $240 \mathrm{~h}$. Figure S6: GO term enrichment of specific DEGs from R6 at each timepoint. (a-d) GO term enrichment of specific DEGs from 6 h, 24 h, 144 h, and 240 h. Figure S7: GO term enrichment of specific DEGs from S8 at each timepoint. (a-d) GO term enrichment of specific DEGs from $6 \mathrm{~h}$, $24 \mathrm{~h}, 144 \mathrm{~h}$, and $240 \mathrm{~h}$. Figure S8: KEGG pathway enrichment of DEGs from R6 and S8 at different timepoints. (a) KEGG pathway enrichment of common DEGs from multiple timepoints from R6 and S8. (b) KEGG pathway enrichment of DEGs from R6 at different timepoints. (c) KEGG pathway enrichment of DEGs from S8 at different timepoints. Figure S9: KEGG pathway enrichment of common and specific DEGs from R6 and S8 at different timepoints. (a) KEGG pathway enrichment of common DEGs identified from R6 and S8 at each timepoint. (b) KEGG pathway enrichment of specific DEGs of R6 at each timepoint compared with S8. (c) KEGG pathway enrichment of specific DEGs of 88 at each timepoint compared with R6. Figure S10: The sample clustering tree of samples collected for WGCNA. Figure S11: Determination of soft threshold for scale-free network. (a) The number scatter plot between soft threshold and the index of scale-free network model. (b) The number scatter plot between soft threshold and mean connectivity. Figure S12: The correlation relationship heatmap between module eigengenes and expression trait at different timepoints. In each brick, the upper numbers are correlation coefficients; lower numbers are $p$ values. Table S1: The reads statistics, mapping and expression genes' summary for R6 and S8 after C. zeina inoculation. Table S2: Gene names of stable common DEGs in R6 at all timepoints, stable common DEGs in S8 at all timepoints, and overlapped common DEGs at all timepoints between R6 and S8. Table S3: Gene information for each module. Table S4: GO term enrichment of genes across all modules. Table S5: KEGG pathway enrichment of genes across all modules. Table S6: Hub genes from gene modules grey60 and purple. Table S7: Putative defense response genes that showed significant differences in expression between the GLS-susceptible and GLS-resistant lines after C. zeina infection. Table S8: QTL information for GLS resistance. Table S9: A list of consistent genes located within QTL for GLS. Table S10: List of genes whose transcription profiles were evaluated by RT-qPCR. For each gene, the forward (fw) and reverse (rev) primer sequences are provided.

Author Contributions: Conceptualization, W.H., M.C. and T.R.; methodology, Y.Z., Y.L. (Yifeng Leng) and L.Y.; investigation, L.D., Y.L. (Yan Li) and Y.H.; resources, B.Z., J.Y., H.L., H.T., J.C., S.G., J.T. and J.K.; writing—original draft preparation, Y.Z. and W.H.; writing—review and editing, Y.Z., 
Y.L. (Yifeng Leng), X.Z. and W.H.; funding acquisition, W.H. All authors have read and agreed to the published version of the manuscript.

Funding: This research was funded by Sichuan Science and Technology Program "Breakthrough maize and sorghum breeding material, method innovation and new variety breeding", grant number 2021YFYZ0017; Sichuan Innovation Team Program of China Agriculture Research System, grant number sccxtd-2021-02; Special financial project of Sichuan Province: Cultivation and industrialization of new environmentally friendly green maize varieties; Demonstration and popularization of new silage maize varieties with high yield and good quality in Danba county, Tibetan area, grant number 2020ZHFP0074; Modern agricultural science and technology and product industrialization demonstration project of Sichuan Academy of Agricultural Sciences: industrialization of Maize Haploid (DH) engineering breeding technology; Pilot ripening and demonstration transformation project of scientific and technological achievements of Sichuan Academy of Agricultural Sciences: integration and popularization of high-quality and high-yield technology of grain and forage silage maize in Western Sichuan Plateau, grant number 2021ZSSF; The Leading Talent Fund Project of Sichuan Academy of Agricultural Sciences, grant number 2019LJRC004; Research Fund for Frontier Science of Sichuan Academy of Agricultural Sciences, grant number 2019QYXK009; Modern agricultural discipline construction promotion project of Sichuan Academy of Agricultural Sciences: Creation of disease resistant and machine harvesting maize breeding materials and method innovation; Sichuan Industrial Research and Development Fund Project (2011): research and development of fresh corn juice; The GMO Program of the Ministry of Agriculture of The People's Republic of China, grant number 2016ZX08003-005; The National Key Development Program, grant number 2016YFD010206-5.

Data Availability Statement: The datasets were deposited in the National Center for Biotechnology Information (NCBI) Sequence Read Archive (SRA) under accession number SRA: SRP111105 (https:/ / www.ncbi.nlm.nih.gov/sra/?term=SRP111105, accessed on 15 September 2021).

Acknowledgments: We thank Weizao Huang, Xiangguo Liu, Xiang Tao, Lujiang Li and Xufeng Li for their advice on the design of this project. We thank GENE DENOVO Co., Ltd. (Guangzhou, China) for their data analysis.

Conflicts of Interest: The authors declare no conflict of interest.

\section{References}

1. Tehon, L.R.; Daniels, E. Notes on the Parasitic Fungi of Illinois-II. Mycologia 1925, 17, $240-249$.

2. Payne, G.; Duncan, H.; Adkins, C. Influence of tillage on development of gray leaf spot and number of airborne conidia of Cercospora zeae-maydis. Plant Dis. 1987, 71, 329-332. [CrossRef]

3. De Nazareno, N.; Lipps, P.; Madden, L. Effect of levels of corn residue on the epidemiology of gray leaf spot of corn in Ohio. Plant Dis. 1993, 77, 67-70. [CrossRef]

4. Elwinger, G.F.; Johnson, M.W.; Hill, R.R., Jr.; Ayers, J.E. Inheritance of Resistance to Gray Leaf Spot of Corn. Crop Sci. 1990, 30, 350-358. [CrossRef]

5. Donahue, P.J.; Stromberg, E.L.; Myers, S.L. Inheritance of Reaction to Gray Leaf Spot in a Diallel Cross of 14 Maize Inbreds. Crop Sci. 1991, 31, 926-931. [CrossRef]

6. Shi, L.; Lv, X.; Weng, J.; Zhu, H.; Liu, C.; Hao, Z.; Zhou, Y.; Zhang, D.; Li, M.; Ci, X.; et al. Genetic characterization and linkage disequilibrium mapping of resistance to gray leaf spot in maize (Zea mays L.). Crop J. 2014, 2, 132-143. [CrossRef]

7. Latterell, F.M.; Rossi, A.E. Gray leaf spot of corn: A disease on the move. Plant Dis. 1983, 67, 842-847. [CrossRef]

8. Lehmensiek, A.; Esterhuizen, A.M.; van Staden, D.; Nelson, S.W.; Retief, A.E. Genetic mapping of gray leaf spot (GLS) resistance genes in maize. Theor. Appl. Genet. 2001, 103, 797-803. [CrossRef]

9. Ward, J.M.J.; Stromberg, E.L.; Nowell, D.C.; Nutter, F.W. Gray leaf Spot: A Disease of Global Importance in Maize Production. Plant Dis. 1999, 83, 884-895. [CrossRef]

10. Berger, D.K.; Carstens, M.; Korsman, J.N.; Middleton, F.; Kloppers, F.J.; Tongoona, P.; Myburg, A.A. Mapping QTL conferring resistance in maize to gray leaf spot disease caused by Cercospora zeina. BMC Genet. 2014, 15, 1-12. [CrossRef]

11. Benson, J.M.; Poland, J.A.; Benson, B.M.; Stromberg, E.L.; Nelson, R.J. Resistance to Gray Leaf Spot of Maize: Genetic Architecture and Mechanisms Elucidated through Nested Association Mapping and Near-Isogenic Line Analysis. PLoS Genet. 2015, 11, e1005045. [CrossRef] [PubMed]

12. Mammadov, J.; Sun, X.; Gao, Y.; Ochsenfeld, C.; Bakker, E.; Ren, R.; Flora, J.; Wang, X.; Kumpatla, S.; Meyer, D.; et al. Combining powers of linkage and association mapping for precise dissection of QTL controlling resistance to gray leaf spot disease in maize (Zea mays L.). BMC Genom. 2015, 16, 916. [CrossRef] [PubMed]

13. Kuki, M.C.; Scapim, C.A.; Rossi, E.S.; Mangolin, C.A.; Amaral Júnior, A.T.d.; Pinto, R.J.B. Genome wide association study for gray leaf spot resistance in tropical maize core. PLoS ONE 2018, 13, e0199539. [CrossRef] [PubMed] 
14. Juliatti, F.C.; Pedrosa, M.G.; Silva, H.D.; da Silva, J.V.C. Genetic mapping for resistance to gray leaf spot in maize. Euphytica 2009, 169, 227-238. [CrossRef]

15. Zhang, Y.; Xu, L.; Fan, X.; Tan, J.; Chen, W.; Xu, M. QTL mapping of resistance to gray leaf spot in maize. Theor. Appl. Genet. 2012, 125, 1797-1808. [CrossRef] [PubMed]

16. Liu, L.; Zhang, Y.D.; Li, H.Y.; Bi, Y.Q.; Yu, L.J.; Fan, X.M.; Tan, J.; Jeffers, D.P.; Kang, M.S. QTL Mapping for Gray Leaf Spot Resistance in a Tropical Maize Population. Plant Dis. 2015, 100, 304-312. [CrossRef]

17. Welgemoed, T.; Pierneef, R.; Sterck, L.; Van de Peer, Y.; Swart, V.; Scheepers, K.D.; Berger, D.K. De novo Assembly of Transcriptomes From a B73 Maize Line Introgressed With a QTL for Resistance to Gray Leaf Spot Disease Reveals a Candidate Allele of a Lectin Receptor-Like Kinase. Front. Plant Sci. 2020, 11, 191. [CrossRef] [PubMed]

18. Kibe, M.; Nair, S.K.; Das, B.; Bright, J.M.; Makumbi, D.; Kinyua, J.; Suresh, L.M.; Beyene, Y.; Olsen, M.S.; Prasanna, B.M.; et al. Genetic Dissection of Resistance to Gray Leaf Spot by Combining Genome-Wide Association, Linkage Mapping, and Genomic Prediction in Tropical Maize Germplasm. Front. Plant Sci. 2020, 11, 1602. [CrossRef]

19. Du, L.; Yu, F.; Zhang, H.; Wang, B.; Ma, K.; Yu, C.; Xin, W.; Huang, X.; Liu, Y.; Liu, K. Genetic mapping of quantitative trait loci and a major locus for resistance to grey leaf spot in maize. Theor. Appl. Genet. 2020, 133, 2521-2533. [CrossRef]

20. Chen, L.; Liu, L.; Li, Z.; Zhang, Y.; Kang, M.S.; Wang, Y.; Fan, X. High-density mapping for gray leaf spot resistance using two related tropical maize recombinant inbred line populations. Mol. Biol. Rep. 2021, 48, 3379-3392. [CrossRef]

21. Xu, L.; Zhang, Y.; Shao, S.; Chen, W.; Tan, J.; Zhu, M.; Zhong, T.; Fan, X.; Xu, M. High-resolution mapping and characterization of qRgls2, a major quantitative trait locus involved in maize resistance to gray leaf spot. BMC Plant Biol. 2014, 14, 230. [CrossRef] [PubMed]

22. Zhang, X.; Yang, Q.; Rucker, E.; Thomason, W.; Balint-Kurti, P. Fine mapping of a quantitative resistance gene for gray leaf spot of maize (Zea mays L.) derived from teosinte (Z. mays ssp. parviglumis). Theor. Appl. Genet. 2017, 130, 1285-1295. [CrossRef]

23. Lv, X.; Song, M.; Cheng, Z.; Yang, X.; Zhang, X.; Zhou, Z.; Zhang, C.; Zheng, L.; Li, Y.; Lei, K.; et al. qGLS1.02, a novel major locus for resistance to gray leaf spot in maize. Mol. Breed. 2020, 40, 59. [CrossRef]

24. Sun, H.; Zhai, L.; Teng, F.; Li, Z.; Zhang, Z. qRgls1.06, a major QTL conferring resistance to gray leaf spot disease in maize. Crop J. 2021, 9, 342-350. [CrossRef]

25. Dodds, P.N.; Rathjen, J.P. Plant immunity: Towards an integrated view of plant-pathogen interactions. Nat. Rev. Genet. 2010, 11, 539-548. [CrossRef]

26. Mauch-Mani, B.; Slusarenko, A.J. Production of Salicylic Acid Precursors Is a Major Function of Phenylalanine Ammonia-Lyase in the Resistance of Arabidopsis to Peronospora parasitica. Plant Cell 1996, 8, 203-212. [CrossRef]

27. Vogt, T. Phenylpropanoid Biosynthesis. Mol. Plant 2010, 3, 2-20. [CrossRef]

28. Zhai, K.; Deng, Y.; Liang, D.; Tang, J.; Liu, J.; Yan, B.; Yin, X.; Lin, H.; Chen, F.; Yang, D.; et al. RRM Transcription Factors Interact with NLRs and Regulate Broad-Spectrum Blast Resistance in Rice. Mol. Cell 2019, 74, 996-1009.e7. [CrossRef]

29. Zhou, X.; Liao, H.; Chern, M.; Yin, J.; Chen, Y.; Wang, J.; Zhu, X.; Chen, Z.; Yuan, C.; Zhao, W.; et al. Loss of function of a rice TPR-domain RNA-binding protein confers broad-spectrum disease resistance. Proc. Natl. Acad. Sci. USA 2018, $115,3174$. [CrossRef]

30. Apel, K.; Hirt, H. REACTIVE OXYGEN SPECIES: Metabolism, Oxidative Stress, and Signal Transduction. Annu. Rev. Plant Biol. 2004, 55, 373-399. [CrossRef] [PubMed]

31. Mittler, R.; Vanderauwera, S.; Suzuki, N.; Miller, G.; Tognetti, V.B.; Vandepoele, K.; Gollery, M.; Shulaev, V.; Van Breusegem, F. ROS signaling: The new wave? Trends Plant Sci. 2011, 16, 300-309. [CrossRef]

32. Zhang, J.; Sun, X. Recent advances in polyphenol oxidase-mediated plant stress responses. Phytochemistry 2021, 181, 112588. [CrossRef]

33. Kaur, G.; Asthir, B. Proline: A key player in plant abiotic stress tolerance. Biol. Plant. 2015, 59, 609-619. [CrossRef]

34. Kim, K.H.; Kang, Y.J.; Kim, D.H.; Yoon, M.Y.; Moon, J.-K.; Kim, M.Y.; Van, K.; Lee, S.-H. RNA-Seq Analysis of a Soybean Near-Isogenic Line Carrying Bacterial Leaf Pustule-Resistant and -Susceptible Alleles. DNA Res. 2011, 18, 483-497. [CrossRef] [PubMed]

35. Bagnaresi, P.; Biselli, C.; Orrù, L.; Urso, S.; Crispino, L.; Abbruscato, P.; Piffanelli, P.; Lupotto, E.; Cattivelli, L.; Valè, G. Comparative Transcriptome Profiling of the Early Response to Magnaporthe oryzae in Durable Resistant vs Susceptible Rice (Oryza sativa L.) Genotypes. PLoS ONE 2012, 7, e51609. [CrossRef]

36. Liu, Y.; Guo, Y.; Ma, C.; Zhang, D.; Wang, C.; Yang, Q. Transcriptome analysis of maize resistance to Fusarium graminearum. BMC Genom. 2016, 17, 477.

37. Wu, X.-j.; Xu, L.; Zhao, P.-f.; Li, N.; Wu, L.; He, Y.; Wang, S.-c. Comparative transcriptome profiling of two maize near-isogenic lines differing in the allelic state for bacterial brown spot disease resistance. J. Integr. Agric. 2015, 14, 610-621. [CrossRef]

38. Meyer, J.; Berger, D.K.; Christensen, S.A.; Murray, S.L. RNA-Seq analysis of resistant and susceptible sub-tropical maize lines reveals a role for kauralexins in resistance to grey leaf spot disease, caused by Cercospora zeina. BMC Plant Biol. 2017, 17, 197. [CrossRef]

39. Kebede, A.Z.; Johnston, A.; Schneiderman, D.; Bosnich, W.; Harris, L.J. Transcriptome profiling of two maize inbreds with distinct responses to Gibberella ear rot disease to identify candidate resistance genes. BMC Genom. 2018, 19, 131. [CrossRef] [PubMed]

40. Yu, Y.; Shi, J.; Li, X.; Liu, J.; Geng, Q.; Shi, H.; Ke, Y.; Sun, Q. Transcriptome analysis reveals the molecular mechanisms of the defense response to gray leaf spot disease in maize. BMC Genom. 2018, 19, 742. [CrossRef] [PubMed] 
41. Wu, G.; Liu, S.; Zhao, Y.; Wang, W.; Kong, Z.; Tang, D. ENHANCED DISEASE RESISTANCE4 Associates with CLATHRIN HEAVY CHAIN2 and Modulates Plant Immunity by Regulating Relocation of EDR1 in Arabidopsis. Plant Cell 2015, 27, 857-873. [CrossRef]

42. Wang, J.; Grubb, L.E.; Wang, J.; Liang, X.; Li, L.; Gao, C.; Ma, M.; Feng, F.; Li, M.; Li, L.; et al. A Regulatory Module Controlling Homeostasis of a Plant Immune Kinase. Mol. Cell 2018, 69, 493-504.e6. [CrossRef]

43. Lin, Z.-J.D.; Liebrand, T.W.H.; Yadeta, K.A.; Coaker, G. PBL13 Is a Serine/Threonine Protein Kinase That Negatively Regulates Arabidopsis Immune Responses. Plant Physiol. 2015, 169, 2950-2962. [CrossRef]

44. Li, J.; Wen, J.; Lease, K.A.; Doke, J.T.; Tax, F.E.; Walker, J.C. BAK1, an Arabidopsis LRR Receptor-like Protein Kinase, Interacts with BRI1 and Modulates Brassinosteroid Signaling. Cell 2002, 110, 213-222. [CrossRef]

45. Roux, M.; Schwessinger, B.; Albrecht, C.; Chinchilla, D.; Jones, A.; Holton, N.; Malinovsky, F.G.; Tör, M.; de Vries, S.; Zipfel, C The Arabidopsis Leucine-Rich Repeat Receptor-Like Kinases BAK1/SERK3 and BKK1/SERK4 Are Required for Innate Immunity to Hemibiotrophic and Biotrophic Pathogens. Plant Cell 2011, 23, 2440-2455. [CrossRef]

46. Heitz, T.; Widemann, E.; Lugan, R.; Miesch, L.; Ullmann, P.; Désaubry, L.; Holder, E.; Grausem, B.; Kandel, S.; Miesch, M.; et al. Cytochromes P450 CYP94C1 and CYP94B3 Catalyze Two Successive Oxidation Steps of Plant Hormone Jasmonoyl-isoleucine for Catabolic Turnover. J. Biol. Chem. 2012, 287, 6296-6306. [CrossRef]

47. Wang, D.; Yu, Y.; Liu, Z.; Li, S.; Wang, Z.; Xiang, F. Membrane-bound NAC transcription factors in maize and their contribution to the oxidative stress response. Plant Sci. 2016, 250, 30-39. [CrossRef]

48. Li, G.; Zhou, J.; Jia, H.; Gao, Z.; Fan, M.; Luo, Y.; Zhao, P.; Xue, S.; Li, N.; Yuan, Y.; et al. Mutation of a histidine-rich calcium-binding-protein gene in wheat confers resistance to Fusarium head blight. Nat. Genet. 2019, 51, 1106-1112. [CrossRef]

49. He, W.; Yang, L.; Leng, Y.; Zhang, B.; Yang, J.; Li, L.; Chen, Y.; Kang, J.; Tang, H.; Deng, L.; et al. QTL mapping for resistance of maize to grey leaf spot. J. Phytopathol. 2018, 166, 167-176. [CrossRef]

50. Meng, X.; Zhang, S. MAPK Cascades in Plant Disease Resistance Signaling. Annu. Rev. Phytopathol. 2013, 51, 245-266. [CrossRef]

51. Shigenaga, A.M.; Berens, M.L.; Tsuda, K.; Argueso, C.T. Towards engineering of hormonal crosstalk in plant immunity. Curr. Opin. Plant Biol. 2017, 38, 164-172. [CrossRef]

52. Ahmad, S.; Veyrat, N.; Gordon-Weeks, R.; Zhang, Y.; Martin, J.; Smart, L.; Glauser, G.; Erb, M.; Flors, V.; Frey, M.; et al. Benzoxazinoid Metabolites Regulate Innate Immunity against Aphids and Fungi in Maize. Plant Physiol. 2011, 157, 317-327. [CrossRef]

53. Dong, X. SA, JA, ethylene, and disease resistance in plants. Curr. Opin. Plant Biol. 1998, 1, 316-323. [CrossRef]

54. Jones, J.D.G.; Dangl, J.L. The plant immune system. Nature 2006, 444, 323-329. [CrossRef] [PubMed]

55. Vlot, A.C.; Dempsey, D.M.A.; Klessig, D.F. Salicylic Acid, a Multifaceted Hormone to Combat Disease. Annu. Rev. Phytopathol. 2009, 47, 177-206. [CrossRef] [PubMed]

56. Sanseverino, W.; Roma, G.; De Simone, M.; Faino, L.; Melito, S.; Stupka, E.; Frusciante, L.; Ercolano, M.R. PRGdb: A bioinformatics platform for plant resistance gene analysis. Nucleic Acids Res. 2009, 38 (Suppl. 1), D814-D821. [CrossRef] [PubMed]

57. Rehmany, A.P.; Gordon, A.; Rose, L.E.; Allen, R.L.; Armstrong, M.R.; Whisson, S.C.; Kamoun, S.; Tyler, B.M.; Birch, P.R.J.; Beynon, J.L. Differential Recognition of Highly Divergent Downy Mildew Avirulence Gene Alleles by RPP1 Resistance Genes from Two Arabidopsis Lines. Plant Cell 2005, 17, 1839-1850. [CrossRef]

58. Mackey, D.; Holt, B.F.; Wiig, A.; Dangl, J.L. RIN4 Interacts with Pseudomonas syringae Type III Effector Molecules and Is Required for RPM1-Mediated Resistance in Arabidopsis. Cell 2002, 108, 743-754. [CrossRef]

59. Serrano, M.; Hubert, D.A.; Dangl, J.L.; Schulze-Lefert, P.; Kombrink, E. A chemical screen for suppressors of the avrRpm1-RPM1dependent hypersensitive cell death response in Arabidopsis thaliana. Planta 2010, 231, 1013-1023. [CrossRef]

60. Eulgem, T.; Somssich, I.E. Networks of WRKY transcription factors in defense signaling. Curr. Opin. Plant Biol. 2007, 10, 366-371. [CrossRef]

61. Casey, R.; Hughes, R.K. Recombinant Lipoxygenases and Oxylipin Metabolism in Relation to Food Quality. Food Biotechnol. 2004, 18, 135-170. [CrossRef]

62. Solano, R.; Gimenez-Ibanez, S. Nuclear jasmonate and salicylate signaling and crosstalk in defense against pathogens. Front. Plant Sci. 2013, 4, 72 .

63. Maroof, M.S.; Van Scoyoc, S.; Yu, Y.; Stromberg, E. Gray leaf spot disease of maize: Rating methodology and inbred line evaluation. Plant Dis. 1993, 77, 583-587. [CrossRef]

64. Wang, Z.; Li, J.Y.; Jia, C.H.; Li, J.P.; Xu, B.Y.; Jin, Z.Q. Molecular cloning and expression of four phenylalanine ammonia lyase genes from banana interacting with Fusarium oxysporum. Biol. Plant. 2016, 60, 459-468. [CrossRef]

65. Beers, R.F.; Sizer, I.W. A spectrophotometric method for measuring the breakdown of hydrogen peroxide by catalase. J. Biol. Chem. 1952, 195, 133-140. [CrossRef]

66. Upadhyaya, A.; Sankhla, D.; Davis, T.D.; Sankhla, N.; Smith, B.N. Effect of Paclobutrazol on the Activities of some Enzymes of Activated Oxygen Metabolism and Lipid Peroxidation in Senescing Soybean Leaves. J. Plant Physiol. 1985, 121, 453-461. [CrossRef]

67. Bates, L.S.; Waldren, R.P.; Teare, I.D. Rapid determination of free proline for water-stress studies. Plant Soil 1973, 39, $205-207$. [CrossRef]

68. Kim, D.; Pertea, G.; Trapnell, C.; Pimentel, H.; Kelley, R.; Salzberg, S.L. TopHat2: Accurate alignment of transcriptomes in the presence of insertions, deletions and gene fusions. Genome Biol. 2013, 14, R36. [CrossRef] 
69. Li, B.; Dewey, C.N. RSEM: Accurate transcript quantification from RNA-Seq data with or without a reference genome. BMC Bioinform. 2011, 12, 323. [CrossRef] [PubMed]

70. Robinson, M.D.; McCarthy, D.J.; Smyth, G.K. edgeR: A Bioconductor package for differential expression analysis of digital gene expression data. Bioinformatics 2009, 26, 139-140. [CrossRef]

71. Schmittgen, T.D.; Livak, K.J. Analyzing real-time PCR data by the comparative CT method. Nat. Protoc. 2008, 3, 1101-1108. [CrossRef]

72. Langfelder, P.; Horvath, S. WGCNA: An R package for weighted correlation network analysis. BMC Bioinform. 2008, 9, 559. [CrossRef] [PubMed]

73. Shannon, P.; Markiel, A.; Ozier, O.; Baliga, N.S.; Wang, J.T.; Ramage, D.; Amin, N.; Schwikowski, B.; Ideker, T. Cytoscape: A Software Environment for Integrated Models of Biomolecular Interaction Networks. Genome Res. 2003, 13, 2498-2504. [CrossRef] [PubMed] 